\title{
Risco, razão tecnológica e o mistério da saúde
}

\author{
Risk, technological reason and the enigma of health \\ Ries go, razón tecnológica y el mist erio de la salud
}

José Ricardo de Carvalho Mesquita Ayres ${ }^{1}$

Ciência, amor, sabedoria, tudo jaz muito longe, sempre imensamente fora de nosso alcance

Meireles (1987, p.608)

\begin{abstract}
Em "O fator de risco na mídia", Vaz et al. brindam-nos com uma fecunda reflexão acerca de como uma das mais impactantes construções conceituais em saúde na modernidade, o conceito epidemiológico de risco, associada a um poderoso meio de comunicação, o jornalismo da grande mídia, participa da construção da experiência de saúde-doença-cuidado nas culturas ocidentais contemporâneas. A argumentação nos conduz por um labirinto de questões de grande complexidade, ao qual somos remetidos toda vez que nos empenhamos no esforço de compreensão de algum aspecto dessa nossa modernidade tardia. Mas a arte dos autores, com base no rigor das construções conceituais filosóficas, joga uma luz renovada nesses labirintos, alimentando nossa capacidade de reflexão sobre uma série de aspectos com os quais lidamos no cotidiano das práticas de saúde. Mais do que isso, e contrariando uma tendência muito comum no filosofar contemporâneo, os autores não se eximem de um ativo posicionamento ético que explicita, simultaneamente, uma totalidade compreensiva, convidando-nos a não, simplesmente, concordar ou discordar de suas construções, mas a nos posicionarmos, também nós, em relação a elas, enriquecendo-as não como "descoberta", mas como experiência.
\end{abstract} 1 Professor, departamento de Medicina Preventiva, Faculdade de Medicina, Univer sidade de São Paulo (FMUSP), São Paulo, SP.
¿rcayres@usp.br>

Avenida Doutor Arnaldo, 455, sala 2217

Cerqueira César - São Paulo, SP

01.246-903

154 Inteface- Comunic, Saúde, Educ, v.11, n.21, p.145-63, jan/abr 2007 
A frase final expressa o convite fundamental do ensaio à reflexão: "Talvez a dívida que tenhamos contraído ao nascer seja a de habitar o mistério de estar vivo; talvez a redução da vida ao esforço de evitar a morte seja um modo de impedir que habitemos o mistério". Cada parte da construção do texto elucida e é elucidada por esta proposição. Tanto a interpretação das implicações epistemológicas da narrativa do risco, quanto as implicações morais dessa narrativa para nossas práticas cotidianas de saúde, têm sua compreensão apoiada nesta idéia central: a de que, no ímpeto moderno de dominarmos o adoecimento, deixamos de habitar o mistério da nossa própria existência. Assim, seja como apreensão e explicação dos fenômenos de saúde, seja como prescrição dos "que fazer" frente a eles, a narrativa midiática do risco patrocina um auto-exílio de nossa ocupação cotidiana com saúde em um território de existência virtual, onde uma permanente e generalizada quase-doença, que só podemos surpreender na singularidade do que cada um de nós faz, pensa e sente, nos mantém ocupados em vigilantes cálculos sobre como alcançar a boa vida. Enquanto isso, a vida, boa ou não, acontece.

Parece-me, então, que a compreensão e discussão do artigo reclamam a reflexão sobre a própria idéia de mistério e sobre a relação de nossos procedimentos racionais - entre eles a ciência e a filosofia - com essa dimensão de nossa existência. Entendo o mistério da vida humana como essa inesgotável e imprevisível vocação que temos de experimentar e compartilhar a "presentificação" das experiências passadas de que somos constituídos, com diferentes graus e modos de (in)consciência, em formas próprias e, a cada vez, novas de existir, as quais nos projetam rumo a experiências não vividas e não antecipáveis, em processos de contínua e mútua reconstrução eu-outro-mundo. A consciência acerca desses processos de reconsotrução, sempre em curso e nunca completamente antecipáveis, por sua vez, só pode ser um compreender com base no incompreensível, um ponderar desde o imponderável, um afirmar-se como existente contra a certeza da "impermanência". Assumir em sua radicalidade esse caráter simultaneamente pragmático, existencial e intersubjetivo de uma consciência que se projeta rumo ao não vivido desde experiências vividas pareceme um passo necessário para efetivamente habitar o mistério da existência humana. Ao fazê-lo, somos levados a compreender nossos procedimentos racionais - incluídas aí as ciências e as filosofias - não como um desvelar do mistério do mundo, mas tampouco como ilusão ou embuste, e sim como um incessante diálogo com o mistério do mundo, nas palavras de Morin (1994). Sendo assim, é possível compreender o exílio de que nos falam os autores, como uma espécie de diálogo "truncado", no qual mistério e verdade trocam de lugar, perdendo-se nessa troca a própria gênese dialógica que os articula. $O$ mistério, ou o incognoscível, parece não mais haver, apenas o (ainda) não-conhecido existe. Por paradoxal que pareça, a verdade, expressão do conhecido, também já não pode existir, já que as "insurgências" e "indisciplinas" do desconhecido a tornam sempre frágil, relativa,... misteriosa. Os procedimentos racionais criam, então, uma permanente $e$ insegura ausência de mistério. Do ponto de vista epistemológico, a razão passa a compreender-se como um dimensionamento da incerteza; e, do ponto de vista moral, o que se pede é que cada um de nós vigie, que esteja fazendo sempre o melhor uso da maior quantidade possível das mais seguras crenças.

Aceitando a tese central dos autores, gostaria de problematizar dois aspectos que me parecem relevantes para dar respostas conseqüentes à reflexão proposta. Ambos dizem respeito ao alcance da compreensão do fenômeno discutido. Nesse sentido, minha primeira questão é: Até que ponto o processo analisado pelos autores é uma decorrência da emergência do risco epidemiológico e sua repercussão midiática? Não será a problemática central do ensaio mais abrangente do que o risco epidemiológico e sua ampliação midiática?

Os autores focalizam, na passagem à modernidade, as tendências que examinam criticamente em seu ensaio. Em síntese, estas são: o ideal de conhecimento como domínio do futuro, a centralidade do raciocínio probabilístico nesse conhecimento, e o caráter 
individualista e universal do uso desse conhecimento. Compreendem essas tendências como expressão de uma "vacância do divino", tanto do ponto de vista moral quanto epistemológico. Do ponto de vista moral porque, com a vacância, não haveria mais qualquer fiador do sofrimento ou garantia de redenção das dores; a responsabilidade, a partir de então, seria de cada um, com base em condutas adequadas, inspiradas pelo uso da razão (mantida a lógica da doença como pecado, e do cuidado da saúde como ascese). Do ponto de vista epistemológico, porque Deus não mais forneceria bases metafísicas seguras para sustentar o conhecimento positivo, só restando a perspectiva finita e falha do sujeito que conhece. Nesse sentido, pergunto aos autores: Não seriam mais arcaicas as razões desse movimento? A vacância do divino, promovida pelos modernos, não seria apenas um "caso particular" de uma busca de explicação e domínio da existência, iniciada na península grega em torno do século $V$ a.C., que acaba sempre por produzir uma existência virtual, com base nas abstrações conceituais e fundamentações metafísicas de cada época?

Faço essa indagação por uma série de razões. A primeira delas refere-se à própria passagem em que os autores apontam, nas medicinas moderna e contemporânea, uma secularização da interpretação da doença como pecado: "Identificar uma causa de morte é estipular aquilo cuja ausência permitiria ao indivíduo manter-se em vida. Essa compreensão de causa expressa, portanto, a laicização da esperança cristã de salvação, ao transformar o sonho de vida após a morte no empenho por não morrer." Mas a compreensão da doença como pecado não foi, por sua vez, uma tradução, no contexto cristão, de um interesse atávico de sobrevivência, de um desejo de imortalidade, que levou os gregos à busca do logos? Logos ou Verbo divino não são, ambos, expressão de um mesmo projeto de insubmissão à impermanência, tendo a razão como fiadora?

Talvez isso pareça uma leitura um tanto frankfurtiana da questão - ou heideggeriana, dependendo do acento que se the dê. Na verdade, sem pretensão nem competência para incursões histórico-filosóficas tão ambiciosas, o que me importa aqui destacar é que, a depender do significado que atribuamos às inflexões moderna e contemporânea dos saberes e práticas de saúde, os remédios para o exílio na insegura e permanente ausência de mistério e na quase-doença generalizada serão também modificados. Então, perguntando de outra forma, caberia questionar: O problema fundamental é o fator de risco e a mídia, ou é nossa compreensão das relações das ciências com a existência e com as dimensões moral-práticas da vida?

Imagino que os autores recusem essa dicotomização e prefiram uma formulação do tipo: Que sentido o fator de risco na mídia imprime, efetivamente, à construção da compreensão ocidental acerca do significado das ciências e de suas implicações moral-práticas? A mim esta formulação agrada mais. Contudo, não me parece ocioso distinguir essa espécie de "sobredeterminação" da aventura racional/científica ocidental sobre esses movimentos mais particulares, sob pena de não levarmos à radicalidade 0 tipo de reflexão reconstrutiva que os nossos tempos estão a reclamar e/ou de subvalorizarmos ou supervalorizarmos inflexões históricas relevantes para a tarefa.

Nesse sentido, cabe indagar se parte substantiva das implicações prático-morais atribuídas pelos autores ao risco epidemiológico-midiático não poderia ser identificada já no final da Antigüidade Clássica. Foucault (2002) aponta, no "cuidado de si", tal como desenvolvido em torno do século II da era cristã, uma "tecnologia de si" que imprime já um sentido individualizador e racional-controlista às práticas de saúde (que Galeno se encarrega de disseminar como doutrina médica, na Higiene). Se é verdade que, aqui, ainda não se colocava a questão de uma quase-doença generalizada, certamente, já está colocada a questão da negação do mistério da morte e do adoecimento pela via de uma aposta no poder redentor do logos (não pela conexão direta deste com a vontade de Deus, mas com a dinâmica da physis). Portanto, um primeiro aspecto que precisa 
ser compreendido e reconstruído é, para além de qualquer forma específica que ela veio a tomar na contemporaneidade, o lugar e o alcance dessa aspiração racional na construção da saúde, e seus traços individualizantes.

Mas os autores distinguem e valorizam analiticamente não apenas a inflexão do medievo à modernidade, como também as concepções e práticas de saúde na passagem do moderno ao contemporâneo. Apontam, com agudeza, deslocamentos importantes nas concepções de causalidade e temporalidade com que trabalham os modernos e os contemporâneos, com implicações para as práticas de cuidado - para os modernos, fora da experiência do sofrimento, não existia doença e, por isso, havia descontinuidade entre momentos de cuidado e momentos de descuido, enquanto, para os contemporâneos, há um estado generalizado de quase-doença, sugerindo uma atitude de constante cuidar-se.

Aqui localizo minha segunda questão. De novo, penso que a busca do mais particular da inflexão não deve perder de vista um relevante movimento de base. Os autores valorizam a mudança da ênfase das doenças infecciosas às doenças crônico-degenerativas (câncer de pulmão, foi o exemplo usado) na diferenciação entre o raciocínio causal-eficiente das ciências da saúde modernas e o raciocínio probabilístico das ciências contemporâneas, destacando aí a temporalidade, isto é, o dilatado intervalo entre exposição e efeito, como elementos que, com a ajuda da mídia, consolidam e disseminam a noção de quasedoença. Sem discordar dos efeitos apontados, penso que sua adequada compreensão reclama aspectos historicamente anteriores e/ou mais abrangentes que os apontados.

Julgo que, no pressuposto moderno da continuidade qualitativa entre o normal e o patológico, entendendo-se este último como uma variação quantitativa de fenômenos apreensíveis no organismo normal (Canguilhem, 1982), já se encontram as bases ideológicas e epistemológicas da quase-doença generalizada. Especialmente desde Claude Bernard, tratar a doença é restabelecer a economia normal do organismo e, de modo articulado, cuidar da saúde é identificar e manter as condições "ótimas" dessa economia. O securitarismo das sociedades ocidentais contemporâneas, sua vontade de "colonizar o futuro" (Giddens, 1991), se encarregou de aumentar, de forma exponencial, essa necessidade de regulação e vigilância constantes do controle da saúde/doença. É aqui que me parece residir, essencialmente, o interesse no conceito epidemiológico de risco, essa espécie de "macroscópio" das ciências biomédicas. Penso que a aplicação de métodos probabilísticos ao raciocínio causal em saúde, realizado pelo conceito de risco, foi o resultado da expansão dessa necessidade de controle tecnológico a regiões do conhecimento nas quais os procedimentos científicos não logravam construções conceituais ou experimentais conclusivas e onde, não obstante, interesses instrumentais eram evidentes e socialmente prementes (Ayres, 2002). Assim, não apenas lacunas temporais, mas também espaciais, fisiológicas, sociais etc., puderam ser contornadas, abrindo caminho para a produção de saberes instrumentais. A explicação dos processos de saúde-doença, cada vez mais apoiada na epidemiologia, não abandonou substantivamente seu caráter causal-eficiente (Almeida Filho, 1992), embora certamente tenha enfraquecido sua metafísica mecanicista. O que a inclusão da probabilidade nas ciências da saúde realizou, ao quantificar incertezas contidas nas "associações causais", foi uma expansão do alcance tecno-normativo das práticas de saúde sem precedentes, apoiada em um impressionante aumento da versatilidade especulativa de suas ciências.

Alguns elementos históricos sustentam minha posição. Veja-se, por exemplo (e aqui eu divirjo de algumas afirmações dos autores), que o conceito de risco antecede as investigações sobre câncer de pulmão, em meados do século XX, apesar de começar a experimentar, nesse período, um processo de intensa formalização (Ayres, 2002). O risco começa a surgir na retórica epidemiológica ainda no início do século $X X$, a propósito de situações inespecíficas de insalubridade - para doenças infecciosas e em situações de longo prazo. Assume suas primeiras formas conceituais mais estáveis, já incorporando métodos probabilísticos, na década de 30 daquele século, especialmente por meio de 
estudos de doenças infecciosas, como os de Frost, acerca da tuberculose, os de Doull, sobre difteria, entre outros. Sua elaboração foi impulsionada justamente pela necessidade de desenvolver tecnologias de controle dessas doenças contornando, conceitual e empiricamente, algumas mediações envolvidas na cadeia causal dessas doenças, de difícil mensuração e complexo controle, como os determinantes sociais.

Com estas observações, desejo defender também a posição de que a reflexão crítica acerca do risco epidemiológico, teoria causal, probabilismo, temporalidade, entre outros aspectos relevantes, não deve passar ao largo desse paroxismo tecnológico da racionalidade contemporânea nas ciências da saúde. Não, obviamente, no sentido de recusar o poder de gerar tecnologias com base nas ciências, mas no sentido habermasiano (Habermas, 1988) de dar visibilidade e trazer ao debate público as correlativas escolhas, valores e implicações para o que fazer cotidiano, sempre subjacentes a qualquer racionalidade tecnológica e que jamais se deixam apreender e resolver pelos desenvolvimentos imanentes de sua lógica sistêmica. Distinguir e interrelacionar, num só movimento, a dimensão tecnológica da razão (meio de transformação instrumental do mundo), a dimensão dialógica da razão (meio de construção de mundos e de intersubjetividades) e o que sempre há de não racional e inefável em cada uma destas dimensões, parece-me ser um desafio central para que possamos experimentar, com intensidade, o mistério do mundo e da saúde, incluindo-se, aí, as construções tecnológicas e dialógicas alcançadas ou vislumbradas ao longo da história humana - tão intrigantes e surpreendentes quanto tudo aquilo em que não logram tocar.

\section{Referências}

ALMEIDA FILHO, N. A clínica e a epidemiologia. Salvador: APCE/Abrasco, 1992.

AYRES, J.R.C.M. Sobre o risco. São Paulo: Hucitec, 2002.

CANGUILHEM, G. O normal e o patológico. Rio de Janeiro: Forense-Universitária, 1982.

FOUCAULT, M. História da sexualidade III. O cuidado de si. Rio de Janeiro: Graal, 2002.

GIDDENS, A. Modernity and self identity. Cambridge: Polity Press, 1991.

HABERMAS, J. Teoría de la acción comunicativa. Madrid: Taurus, 1988.

MEIRELES, C. Obra poética. Rio de Janeiro: Nova Aguilar, 1987.

MORIN, E. Ciência com consciência. Lisboa: Publicações Europa-América, 1994. 